\title{
The clinical relevance of bifid and trifid mandibular canals
}

\author{
K. Mizbah • N. Gerlach • T. J. Maal • S. J. Bergé • \\ Gert J. Meijer
}

Received: 22 March 2011 / Accepted: 27 May 2011 /Published online: 23 June 2011

(C) The Author(s) 2011. This article is published with open access at Springerlink.com

\begin{abstract}
Background Bifid mandibular canals (BMC) and trifid mandibular canals (TMC) are variations on the normal anatomy with incidences ranging from $0.08 \%$ to $65.0 \%$. Such aberrations have an important clinical impact. For example, an extra mandibular canal may explain inadequate anesthesia, especially when two mandibular foramina are involved. Furthermore, during mandibular surgery, a second, or even third, neurovascular bundle may be damaged causing paresthesia, neuroma development, or bleeding. Case report Two cases are presented in this article. One patient had a BMC on both sites, and the other patient had a $\mathrm{TMC}$ on one site and a BMC on the other site.

Discussion Initial screening for the presence of a BMC or TMC can be executed by conventional panoramic radiography. BMCs or TMCs are diagnosed, before executing mandibular surgery; additional CBCT scanning is indicated.
\end{abstract}

Keywords Bifid mandibular canal · Trifid mandibular canal $\cdot$ Inferior alveolar nerve

\section{Background}

The inferior alveolar nerve (IAN) is of particular interest to all who work in the field of oral maxillofacial surgery for obvious reasons. For example, a reliable insight in the

K. Mizbah and N. Gerlach equally contributed to this work.

K. Mizbah • N. Gerlach • T. J. Maal · S. J. Bergé •

G. J. Meijer $(\bowtie)$

Department of Oral and Maxillofacial Surgery,

Radboud University Nijmegen Medical Centre 590,

P.O. Box 9101, NL-6500, HB Nijmegen, The Netherlands

e-mail: g.meijer@dent.umcn.nl three-dimensional relationship of the mandibular third molar root with the mandibular canal is essential for an optimal surgical procedure to remove wisdom teeth, thereby taking care to avoid any pressure on the IAN [10]. Also, the IAN may be traumatized by an implant intruding into the canal or penetration by the drill preceding implant placement [28]. In addition, in cases of a bilateral sagittal split osteotomy, three-dimensional information about the IAN may prevent nerve damage during surgery.

In contrast to the panoramic radiography, computed tomography (CT) allows three-dimensional insight. However, drawbacks of computed tomography are the higher radiation dose [23] and elevated financial costs compared to panoramic imaging. Recently, cone beam computed tomography (CBCT) has been introduced in an effort to improve the performance of the conventional $\mathrm{CT}$, such as reducing the radiation dose [2], offering high spatial resolution [17], and decreasing the costs. As the CBCT gains popularity, more anatomical aberrations of the IAN will be recognized and three-dimensionally presented.

As main trunk of the IAN, the trigeminal nerve emerges as the fifth cranial nerve from the lateral surface of the pons in both a motor and a sensory root. Subsequently, the sensory root expands into the trigeminal ganglion, from which three divisions of the nerve arise. As one of these, the mandibular nerve passes through the foramen ovale to the infratemporal fossa, wherein subsequently different branches are sprouted. One of them is the IAN, which enters the lower jaw as a sensible nerve at the mandibular foramen and runs in company with the mandibular vessels in the mandibular canal anteriorly, gradually crossing from a lingual to a more buccal plane. It supplies the mandibular teeth with sensory branches that form into the inferior dental plexus and give off small dental nerves to the teeth [1]. 
Fig. 1 a Panoramic radiograph. b Coronal cross section. c Axial cross section

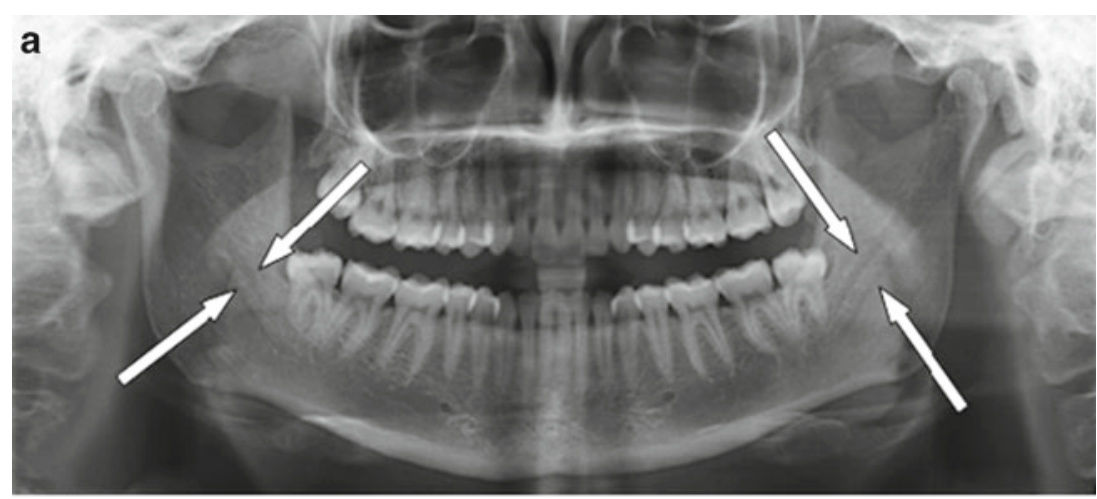

Panoramic radiograph

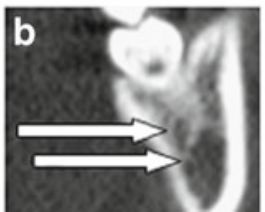

coronal cross-section

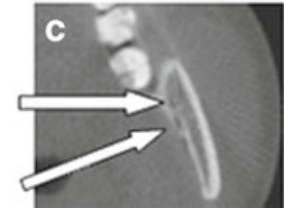

axial cross-section
The cranio-caudal and bucco-lingual positions, as also the branching pattern of the neurovascular bundle, differ within the mandibular body when different mandibles are compared. At the mental foramen, the nerve leaves the corpus mandibula mostly after a short recurrent intraosseous course, creating the so-called anterior loop [9]. The shape, curve, and direction of this terminal segment are quite variable. Before the nerve leaves the corpus mandibula, it gives birth to a small branch as the continuation of the inferior alveolar nerve, which prolongs its course inside the mandible and innervates the mandibular canines and incisors.

Additionally, the position of the mental foramen itself also varies. Nevertheless, it is mostly situated below the apex of the second premolar [1, 10, 12, 28]. Due to its considerable variation in course, it can be difficult to predict the exact position of the IAN, thus frustrating a proper pre-operative planning.

\section{Case report 1}

A 22-year-old healthy female was referred because of pain located at her lower right wisdom tooth. Intra-oral examination revealed inflammation of the pericoronal mucosa (pericoronitis) around the partially erupted molar due to ineffective cleaning. On the routinely performed panoramic radiograph (Fig. 1a), bilaterally, a bifid mandibular canal (BMC) was suggested. This was confirmed by CBCT imaging using axial and coronal cross sections (Fig. 1b, c).

On both sides, two mandibular canals were observed ending into one single mental foramen. The detailed cross section at the right side shows that the lowest canal showed no relation with the apical part of the root. The upper canal, however, was positioned lingually of the root, a sign of high risk for nerve damage [10]. The patient was informed about the presence of this anatomical aberration, an informed consent was given, and 1 week later, the wisdom tooth was
Fig. 2 Panoramic radiograph showing the two mandibular canals (see arrows)

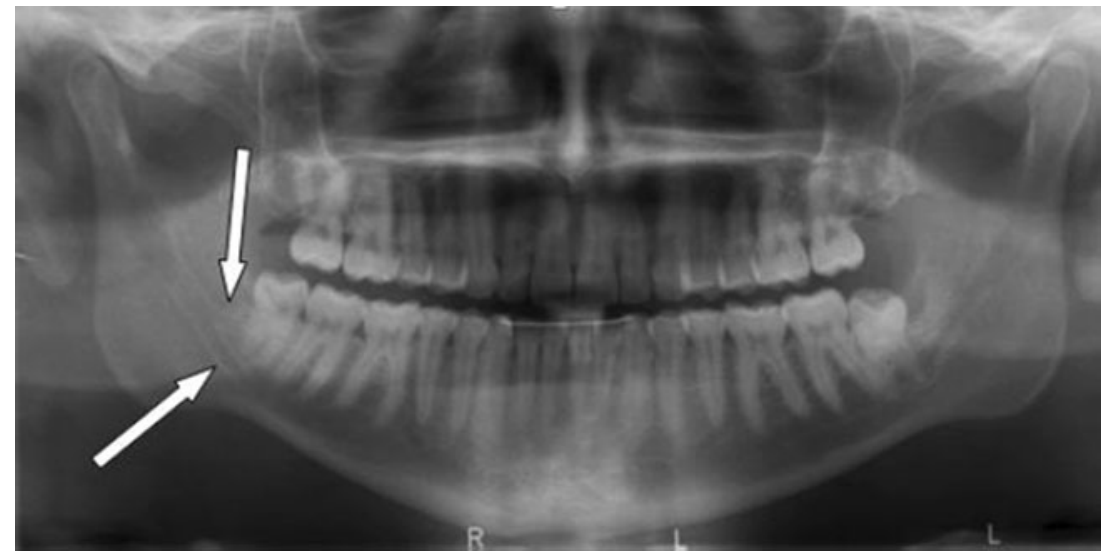


Fig. 3 Showing coronal cross sections. a Before the splitting of the canal. b The bifurcation just started. c Showing two separate canals. d Vertical course of the retromolar canal

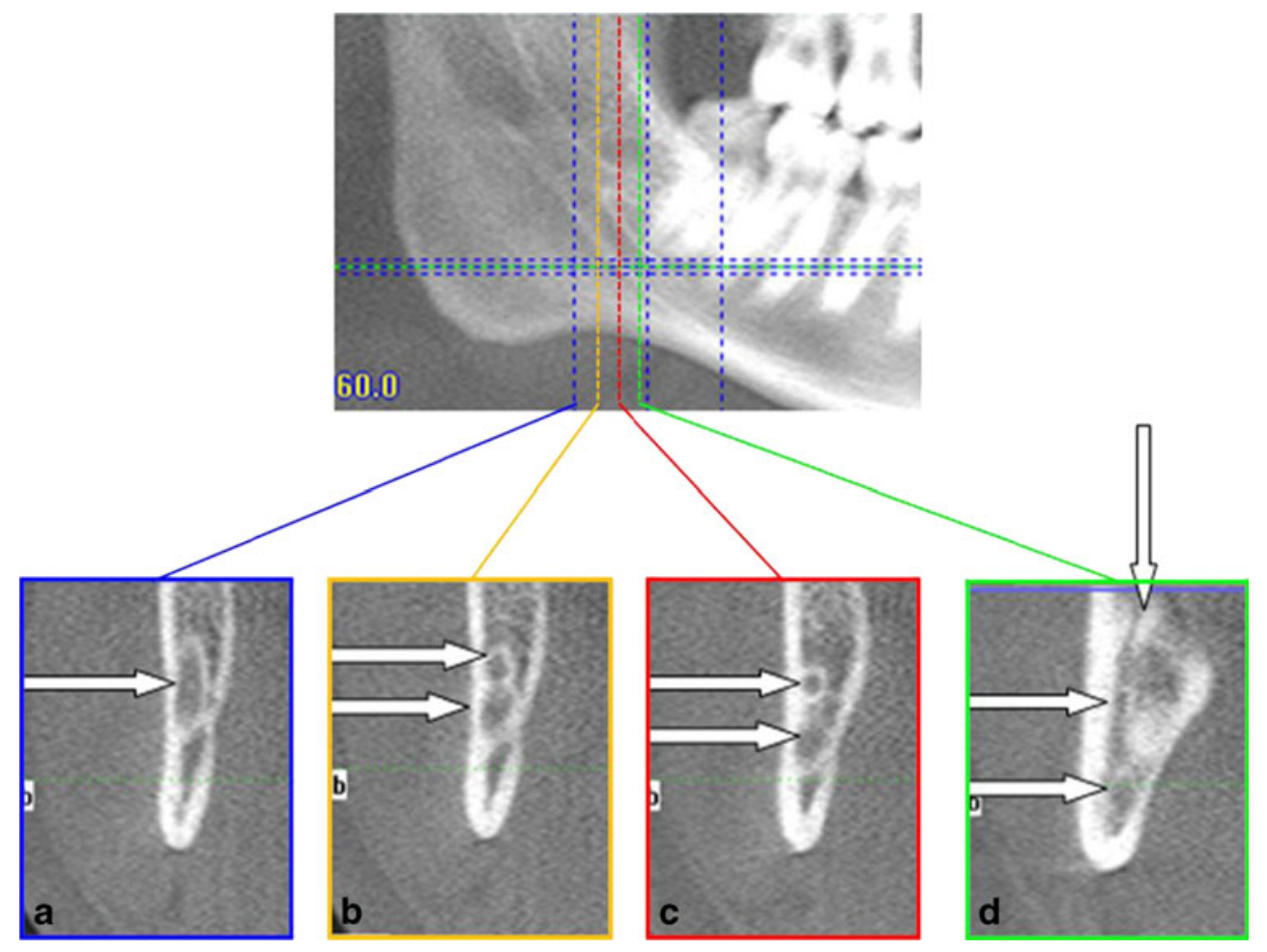

surgically removed. To avoid pressure on the IAN, first, the roots were sectioned and subsequently individually mobilized in a strict buccal direction. Post-operatively, the patient experienced a normal sensibility, and the further course was completely uneventful.

\section{Case report 2}

A 26-year-old healthy male was referred for surgical removal of both his impacted mandibular third molars. Intra-orally at both sides, pericoronitis was observed, causing severe complaints. The pre-surgical panoramic radiograph (Fig. 2) revealed only at the right side a duplicated mandibular canal. Surprisingly, an additional CBCT with coronal cross sections (Fig. 3) elucidated an extra canal on both sides, implicating the presence of two canals (BMC) for the left side and even three canals (trifid mandibular canal, TMC) for the right side. These two unexpected extra canals showed a backward loop to the retromolar region (Fig. 4).

After informing the patient about the risk of IAN damage, it was decided to remove both wisdom teeth in two separate sessions. Both surgical procedures were uneventful, and post-operatively, the patient experienced normal sensibility.

\section{Discussion}

Despite the shortcomings of panoramic radiographs, like distortions and a two-dimensional visualization [24, 25],
Fig. 4 Reconstruction with nerve tracking showing the bifid and trifid mandibular canals

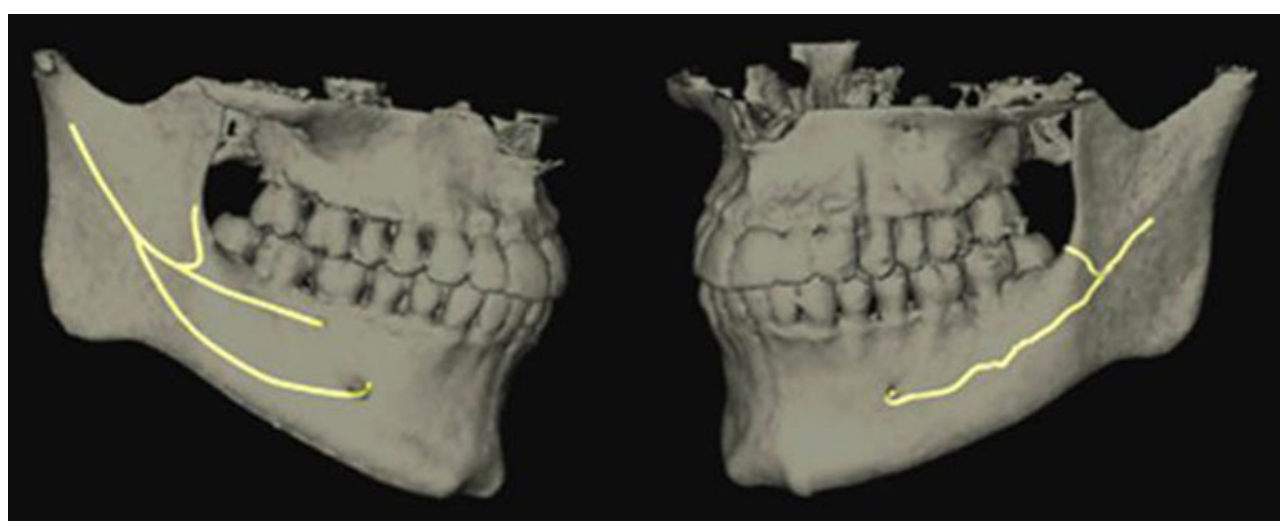


Table 1 The type of study, type of radiography, and the incidence of BMC and TMC are presented

\begin{tabular}{|c|c|c|c|c|}
\hline Author & Type of study & Type of radiography & Incidence of $\mathrm{BMC}$ & Incidence of TMC \\
\hline Auluck, 2007 [3] & Case report & OPT & 5 cases & 1 case \\
\hline \multirow[t]{2}{*}{ Bogdán et al., 2006 [5] } & $\begin{array}{l}\text { Cadaver study } \\
46 \text { dry mandibles }\end{array}$ & - & 8 cases, $17.4 \%$ & 1 case, $2.2 \%$ \\
\hline & 1,000 patients & OPT & 2 cases, $0.2 \%$ & \\
\hline Claeys et al., 2005 [6] & Case report & $\mathrm{CT}$ & 1 case & 0 \\
\hline Dario, 2002 [7] & Case report & OPT & 1 case & 0 \\
\hline Durst et al., $1980[8]$ & 1,024 patients & OPT & 85 cases, $8.3 \%$ & 0 \\
\hline Grover et al., 1983 [11] & 5,000 patients & OPT & 4 cases, $0.08 \%$ & 0 \\
\hline Karamifar et al., 2009 [13] & Case report & OPT & 1 case & 1 case \\
\hline Kaufman et al., 2000 [14] & Case report & $\mathrm{CT}$ & 1 case & 0 \\
\hline Langlais et al., 1985 [16] & 6,000 patients & OPT & 57 cases, $0.95 \%$ & 0 \\
\hline Miloglu et al., 2009 [18] & Case report & $\mathrm{CT}$ & 1 case & 0 \\
\hline Naitoh et al., 2009 [20] & 122 patients & $\mathrm{CBCT}$ & 79 cases, $65 \%$ & 0 \\
\hline Nortje et al., 1977 [21] & 3,612 patients & OPT & 33 cases, $0.9 \%$ & 0 \\
\hline Sanchis et al., 2003 [22] & 2,012 patients & OPT & 7 cases, $0.35 \%$ & 0 \\
\hline Wadhwani et al., 2008 [27] & 2,012 patients & OPT & 2 cases & 0 \\
\hline
\end{tabular}

anatomical variations of the mandibular canal can be detected. However, three-dimensional radiographs offer more insight in the exact position of the canal, specifically about its bucco-lingual position.

Recently, CBCT has been introduced in an effort to compensate the shortcomings of the conventional CT, such as the higher radiation dose, lower spatial resolution, and the higher costs $[4,17]$. In addition, with the use of three-dimensional-image-based planning software, the course of the mandibular canal can be marked at different locations depicting anatomical variations more clearly (Figs. 2 and 3).

Variations of the mandibular canal, such as BMC, are reported with incidences ranging from $0.08 \%$ to $65.0 \%[3$, $5,7,19,20]$ (Table 1). The first-mentioned TMC was only based on a conventional optical projection tomography $\left(\mathrm{OPT}^{3}\right)$, however, not confirmed by CBCT. Causes for misinterpretation underlying a false double-canal radiograph using a conventional OPT may include the imprint of the mylohyoid nerve on the internal mandibular surface, where it separates from the inferior alveolar nerve and travels to the floor of the mouth. Another explanation is the radiologic osteocondensation image produced by the insertion of the mylohyoid muscle into the internal mandibular surface, with a distribution parallel to the dental canal $[15,26]$. The first established case of a TMC was presented in a study on dry mandibles [5].

Identifying aberrant courses of the IAN, and thereby recognizing surgical pitfalls, became much easier by the introduction of CBCT. Obviously, BMCs and TMCs have important clinical implications, for example, in explaining the reason for inadequate anesthesia, especially when two mandibular foramens are involved [11]. Furthermore, planning of third molar removal needs extra attention when bifid or trifid canals are present in that specific area. In addition, damaging a second, or even third, neurovascular bundle can cause complications such as a paresthesia, neuroma, or bleeding.

To conclude, initial screening for the presence of a BMC can be executed by conventional panoramic radiography. In case BMCs are diagnosed, before executing mandibular surgery, additional CBCT scanning is indicated. The CBCT can also reveal any TMCs and gives insight in the exact course of the canals.

Conflict of interest The authors declare that they have no conflict of interest.

Open Access This article is distributed under the terms of the Creative Commons Attribution Noncommercial License which permits any noncommercial use, distribution, and reproduction in any medium, provided the original author(s) and source are credited.

\section{References}

1. Anderson LC, Kosinski TF, Mentag PJ (1991) A review of the intraosseous course of the nerves of the mandible. J Oral Implantol 17:394-403

2. Araki K, Maki K, Seki K, Sakamaki K, Harata Y, Sakaino R, Okano T, Seo K (2004) Characteristics of a newly developed dentomaxillofacial X-ray cone beam CT scanner (CB MercuRay): 
system configuration and physical properties. Dentomaxillofac Radiol 33:51-59

3. Auluck A, Pai KM, Mupparapu M (2007) Multiple mandibular nerve canals: radiographic observations and clinical relevance. Report of 6 cases. Quintessence Int 38:781-787

4. Boeddinghaus R, Whyte A (2008) Current concepts in maxillofacial imaging. Eur J Radiol 66:396-418

5. Bogdán S, Pataky L, Barabás J, Németh Z, Huszár T, Szabó G (2006) Atypical courses of the mandibular canal: comparative examination of dry mandibles and x-rays. J Craniofac Surg $17: 487-491$

6. Claeys V, Wackens G (2005) Bifid mandibular canal: literature review and case report. Dentomaxillofac Radiol 34:55-58

7. Dario LJ (2002) Implant placement above a bifurcated mandibular canal: a case report. Implant Dent 11:258-261

8. Durst JH, Snow JM (1980) Multiple mandibular canals; oddities or fairly common anomalies. Oral Surg Oral Med Oral Pathol 49:272-273

9. Gerlach NL, Meijer GJ, Maal TJ, Mulder J, Rangel FA, Borstlap WA, Berge SJ (2010) Reproducibility of 3 different tracing methods based on cone beam computed tomography in determining the anatomical position of the mandibular canal. J Oral Maxillofac Surg 68:811-817

10. Ghaeminia H, Meijer GJ, Soehardi A, Borstlap WA, Mulder J, Bergé SJ (2009) Position of the impacted third molar in relation to the mandibular canal. Diagnostic accuracy of cone beam computed tomography compared with panoramic radiography. Int J Oral Maxillofac Surg 38:964-971

11. Grover PS, Lorton L (1983) Bifid mandibular nerve as a possible cause of inadequate anesthesia in the mandible. J Oral Maxillofac Surg 41:177-179

12. Hwang K, Lee WJ, Song YB, Chung IH (2005) Vulnerability of the inferior alveolar nerve and mental nerve during genioplasty: an anatomic study. J Craniofac Surg 16:10-14

13. Karamifar K, Shahidi S, Tondari A (2009) Bilateral bifid mandibular canal: report of two cases. Indian J Dent Res 20:235-237

14. Kaufman E, Serman NJ, Wang PD (2000) Bilateral mandibular accessory foramina and canals: a case report and review of the literature. Dentomaxillofac Radiol 29:170-175

15. Kiersch TA, Jordan JE (1973) Duplication of the mandibular canal. Oral Surg Oral Med Oral Pathol 35:133-134
16. Langlais RP, Broadus R, Glass BJ (1985) Bifid mandibular canals in panoramic radiographs. J Am Dent Assoc 110:923-926

17. Ludlow JB, Davies-Ludlow LE, Brooks SL, Howerton WB (2006) Dosimetry of 3 CBCT devices for oral and maxillofacial radiology: CB Mercuray, NewTom 3G and i-CAT. Dentomaxillofac Radiol 35:219-226

18. Miloglu O, Yilmaz AB, Caglayan F (2009) Bilateral bifid mandibular canal: a case report. Med Oral Patol Oral Cir Bucal $14: 244-246$

19. Nakagawa Y, Kobayashi K, Ishii H, Mishima A, Ishii H, Asada K, Ishibashi K (2002) Preoperative application of limited cone beam computerized tomography as an assessment tool before minor oral surgery. Int J Oral Maxillofac Surg 31:322-326

20. Naitoh M, Hiraiwa Y, Aimiya H, Ariji E (2010) Observation of bifid mandibular canal using cone-beam computerized tomography. Int J Oral Maxillofac Implants 24:155-159

21. Nortje CJ, Farman AG, Grotepass FW (1977) Variations in the normal anatomy of the inferior dental (mandibular) canal: a retrospective study of panoramic radiographs from 3612 routine dental patients. Br J Oral Surg 15:55-63

22. Sanchis JM, Pennarrocha M, Soler F (2003) Bifid mandibular canal. J Oral Maxillofac Surg 61:422-424

23. Schulze D, Heiland M, Thurmann H, Adam G (2004) Radiation exposure during midfacial imaging using 4-and 16-slice computed tomography, cone beam computed tomography systems and conventional radiography. Dentomaxillofac Radiol 33:83-86

24. Vasquez L, Saulacic N, Belser U, Bernard JP (2008) Efficacy of panoramic radiographs in the preoperative planning of posterior mandibular implants: a prospective clinical study of 1527 consecutively treated patients. Clin Oral Implants Res 19:81-85

25. Walton JN (2000) Altered sensation associated with implants in the anterior mandible: a prospective study. J Prosthet Dent 83:443-449

26. Wilson S, Johns P, Fuller PM (1984) The inferior alveolar and mylohyoid nerves: an anatomic study and relationship to local anesthesia of the anterior mandibulair teeth. J Am Dent Assoc 108:350-352

27. Wadhwani P, Mathur RM, Kohli M, Sahu R (2008) Mandibular canal variant: a case report. J Oral Pathol Med 37:122-124

28. Worthington P (2004) Injury to the inferior alveolar nerve during implant placement: a formula for protection of the patient and clinician. Int J Oral Maxillofac Implants 19:731-734 